\title{
Mensuração das Elasticidades-preço da Demanda, Cruzada e Renda no Mercado de Etanol Brasileiro: um estudo usando painéis cointegrados ${ }^{1}$
}

\author{
Leonardo Chaves Borges Cardoso² e Maurício Vaz Lobo Bittencourt ${ }^{3}$
}

Resumo: A futura escassez das fontes fósseis de energia não é opinião partilhada por toda a academia, mas a necessidade de fontes energéticas renováveis é, sim, um consenso. Com base nisso, o etanol de primeira geração a partir da cana-de-açúcar brasileira se torna uma excelente alternativa energética por apresentar melhores indicadores nos quesitos intensidade em terras, custo de produção e redução de $\mathrm{CO}_{2}$ em relação a outras culturas para produção de etanol. Porém, não há estudos que estimem a demanda de longo prazo utilizando dados em painel e que obtenham estimativas regionais para as cinco regiões brasileiras. Diante de tal lacuna, este artigo tem por objetivo estimar as elasticidades-preço, renda e cruzada da demanda por etanol, tanto no curto quanto no longo prazo. As estimativas são feitas para todo o Brasil e para as cinco regiões brasileiras, no período de julho de 2001 a julho de 2011, com bases mensais. São usados dados em painel, e as estimativas utilizam como principais estimadores o General Least Squares (GLS) com correção para heterocedasticidade para encontrar as relações de curto prazo e Dynamic Ordinary Least Squares (DOLS) para as de longo prazo. Os resultados indicam que o etanol é um bem elástico a preço, com elasticidade por volta de $-1,42$ e -3,30 para o curto e longo prazo, respectivamente, e que as elasticidades-preço e cruzada de curto prazo aumentaram no período pós-flex.

Palavras-chaves: Econometria de painel, DOLS, etanol, elasticidades de demanda.

Abstract: The future shortage of fossil energy is not shared by the entire academy, but the need of renewable energy sources is a consensus. Based on this, the ethanol from sugarcane

\footnotetext{
1 Versões preliminares deste artigo foram apresentadas nos encontros nacionais da Aber e da Anpec em 2012. Os autores agradecem os importantes comentários e sugestões de Márcia Azanha de Morais, Luciano Nakabashi, Armando Sampaio, Felippe Serigatti, Gervásio dos Santos e Gilberto Silveira Barros Neto, bem como o suporte financeiro da Capes. Os erros, omissões e opiniões são de inteira responsabilidade dos autores.

2 Doutorando pelo Programa de Pós-Graduação em Desenvolvimento Econômico da Universidade Federal do Paraná (PPGDE/UFPR), bolsista da Capes. E-mail: leonardocardoso@ufpr.br

3 Professor no Programa de Pós-Graduação em Desenvolvimento Econômico da Universidade Federal do Paraná (PPGDE/UFPR), Pós-Doutorando na Ohio State University (OSU), bolsista do CNPq. E-mail: mbittencourt@ufpr.br
} 
in Brazil becomes an excellent energy alternative by offering better indicators, such as: less land intensity, lower production costs and larger $\mathrm{CO}_{2}$ reduction when compared with other energy producing crops. However, there are no studies that estimate the long run ethanol demand using panel data or either estimate it at regional level. Therefore, this study aims to estimate the price, income and cross price demand elasticities for ethanol in the short and long run. The estimates are both at national and regional levels for Brazil, from July 2001 to July 2011, on a monthly basis. Panel data econometrics are used and forecasts use the following estimators: General Least Squares (GLS) with correction for heteroscedasticity for short run and Dynamic Ordinary Least Squares (DOLS) for long run. Results indicate that ethanol is price elastic, with elasticity around -1.42 and -3.30 for the short and long run, respectively. There was an increase of cross and price elasticities in the short run in the post-flex period.

Key-words: Panel econometrics, DOLS, ethanol, demand elasticities.

Classificação JEL: C23, D12, Q11, Q21, Q41.

\section{Introdução}

Os anseios por alternativas energéticas aos fósseis vêm aumentando ano a ano. Mesmo a futura escassez dos fósseis não sendo uma opinião partilhada por toda a academia, a necessidade de fontes energéticas mais limpas é, sim, um consenso. Pensando nisso, o etanol de cana-de-açúcar se mostra uma excelente alternativa energética para o Brasil e para o mundo.

No caso do etanol de primeira geração ${ }^{4}$, muito se discute sobre a possibilidade de ele se tornar uma commodity internacional, já que a cultura brasileira ganha nos comparativos com outras matérias-primas para a produção de etanol nos principais quesitos: balanço energético fóssil, redução de emissões de $\mathrm{CO}_{2}$ em comparação com a gasolina e intensidade em terras (GOLDEMBERG e GUARDABASSI, 2009). Além desses critérios, toda e qualquer energia alternativa ainda tem como principal concorrente os fósseis e seus derivados. E, por isso, precisa,

4 As expressões "etanol de primeira geração" e "etanol de segunda geração" referem-se ao modo como o etanol é obtido. No caso da primeira geração, ele é obtido através da fermentação do caldo da cana-de-açúcar. No de segunda geração, a matéria-prima seria o bagaço e a palha da cana. Para extrair os açúcares do bagaço e da palha, seriam utilizados processos de hidrólise ácida ou hidrólise enzimática. Entretanto, esses processos estão sendo aperfeiçoados a fim de serem viáveis economicamente (WORLDWATCH INSTITUTE, 2006). além de ter melhores indicadores ambientais, ser economicamente viável. Esse talvez seja o principal ponto impeditivo à adoção de novas tecnologias. Ou seja, muitas das novas alternativas continuam sendo consideradas tecnologias de backstop ${ }^{5}$ e continuam esperando por avanços que possibilitem a diminuição de custos ou situações de mercado que aumentem os preços dos principais concorrentes. Elas são apostas para o futuro.

É importante destacar que o recente aumento da frota de automóveis tem impacto significativo na economia brasileira, seja na quantidade negativa de externalidades que este causa com o aumento da poluição nas grandes cidades, seja com o aumento na propensão à ocorrência de acidentes, congestionamentos, ou aumento na dependência por considerável e suficiente oferta de combustíveis.

As autoridades governamentais poderiam adotar diversas políticas de modo a amenizar tais efeitos, tentando principalmente reduzir o consumo de gasolina ou reduzindo a poluição dos automóveis. É claro que, pelo lado da redução da poluição, as políticas que poderiam ser adotadas poderiam sugerir medidas de redução na emissão de poluentes pelos fabricantes de automóveis, inspeção frequente dos automóveis, redução nos congestionamentos através de políticas de

\footnotetext{
5 A tecnologia é conhecida, porém não consegue entrar no mercado por ainda não ter preços competitivos.
} 
urbanização e modernização das vias públicas, dentre outras. Tradicionalmente, aumentos nos impostos tem sido mais comuns no caso de políticas visando a redução no consumo de gasolina, além de busca de carros mais eficientes no uso de combustível.

No caso do Brasil, existem algumas alternativas de políticas que não existem em outros países, devido ao uso de etanol como substituto à gasolina, além da elasticidade-preço da demanda por gasolina em outros países ser muito baixa, limitando muito a utilização de tais políticas. De modo a sugerir políticas de redução ou desenvolvimento do mercado de combustíveis em solo brasileiro, as autoridades devem considerar os dois mercados (etanol e gasolina) de forma conjunta.

Conhecer melhor o mercado de etanol, bem como quais os parâmetros da sua demanda de curto e longo prazo, são primordiais para elaboração de políticas públicas, principalmente aquelas ligadas à diminuição de consumo de combustíveis fósseis. Entretanto, a literatura internacional sobre demanda por etanol é muito reduzida se comparada com a de gasolina, o que era de se esperar por conta da sua reduzida importância como substituto à gasolina fora do Brasil (mesmo nos EUA que são os principais consumidores, o etanol não chega a substituir mais que $2,5 \%$ da gasolina consumida ${ }^{6}$.

Considerando apenas os preços ao consumidor, o etanol no Brasil ainda não é uma alternativa viável para todos os estados da nação. Estados não produtores da região Norte, por exemplo, têm consumo de etanol muito reduzido e ainda há muito espaço para expansão da demanda. Por isso, mais do que transformar o etanol em uma commodity internacional, é necessário também atender a demanda reprimida de estados distantes dos centros produtores.

Na literatura nacional não foram encontrados trabalhos que estimassem as elasticidades usando painéis cointegrados, nem trabalhos com estima-

6 Dados disponíveis no U.S. Energy Information Administration - Short Term Energy Outlook (2011). tivas das elasticidades para as regiões. Diante de tal lacuna, o presente artigo tem por objetivo estimar as elasticidades de demanda de curto e longo prazo por etanol no Brasil usando dados em painéis. As estimativas de curto prazo usam o estimador General Least Squares (GLS) com correção para heterocedasticidade e erros autocorrelacionados, mas outros estimadores são reportados para efeito de comparação. As estimativas de longo prazo são obtidas usando técnicas de cointegração em painéis com uso do Dynamic Ordinary Least Squares (DOLS), estimador que também ainda não foi usado na literatura sobre demanda por combustíveis no Brasil. Adicionalmente, este artigo objetiva fazer o mesmo procedimento para as estimativas das elasticidades nas regiões brasileiras, de modo a perceber as diferenças regionais e verificar se houve mudança nos parâmetros por conta da entrada dos carros flex-fuel no mercado.

Além da presente introdução, este artigo conta com uma seção dedicada à contextualização do mercado de etanol, seguido por uma revisão bibliográfica dos trabalhos que estimaram a demanda por combustíveis no Brasil e no mundo. A terceira parte do artigo expõe o modelo a ser estimado, seguida pelos testes econométricos feitos e pelos resultados das estimativas. Na última seção são feitas as considerações finais.

\section{Produção de etanol e mudanças na matriz energética}

A necessidade de diversificação de fontes energéticas é motivada pelo fato de a energia primária consumida no mundo ser fruto, principalmente, do petróleo e do carvão mineral, que totalizam $33,56 \%$ e $29,63 \%$, respectivamente, da energia primária consumida no mundo. Quando se compara fontes renováveis e não renováveis, observa-se que as fontes não renováveis foram historicamente responsáveis por mais de $90 \%$ da energia primária consumida no mundo. Mesmo hoje, com as preocupações ambientais, essa realidade ainda está longe de mudar, sendo que a participação das energias renováveis é de apenas 
Mensuração das Elasticidades-preço da Demanda, Cruzada e Renda no Mercado de Etanol Brasileiro:

um estudo usando painéis cointegrados

Tabela 1. Características de diferentes matérias-primas para produção de etanol

\begin{tabular}{|c|c|c|c|}
\hline Matéria-Prima & Cana-de-açúcar - Brasil & Milho - EUA & Beterraba - EU \\
\hline Balanço Energético Fóssil ${ }^{a}$ & $8,1-10$ & 1,4 & 2,0 \\
\hline Custo de Produção (Euros/100 litros) & 14,48 & 24,83 & 52,37 \\
\hline Redução de $\mathrm{CO}_{2}{ }^{\mathrm{b}}$ & $84 \%$ & $30 \%$ & $40 \%$ \\
\hline Produção Total (bilhões de litros) & 22,5 & 34,0 & 2,7 \\
\hline Área Plantada (milhões de hectares) & 3,40 & 8,13 & 0,49 \\
\hline Produtividade (litros/hectare) & 6.741 & 4.182 & 5.510 \\
\hline
\end{tabular}

Notas: a) Balanço Energético Fóssil (BEF). No BEF, divide-se a quantidade total de energia contida no combustível pela quantidade de energia fóssil total utilizada no processo. Quanto maior o BEF, mais energia fóssil está sendo poupada (WORLDWATCH INSTITUTE, 2006). b) Porcentagem das reduçães de $\mathrm{CO}_{2}$ em comparação com o ciclo completo da gasolina (extração, produção, refino, transporte, distribuição e queima)

Fonte: Goldemberg e Guardabassi (2009).

7,8\% da energia primária mundial (BP, 2011 e IEA 2010).

A Tabela 1 mostra que o etanol da cana-de-açúcar poupa mais energia fóssil na sua produção, tem menor custo em comparação a outras matérias-primas, tem maior redução de emissões de $\mathrm{CO}_{2}$, além de ser menos intensivo em terras do que outras culturas, sendo uma alternativa interessante no curto prazo. Segundo Shikida e Pedrosa (2012), a competitividade do etanol brasileiro deve-se em boa medida às escolhas do passado e às trajetórias que se formaram a partir dessas. O Proálcool seria o marco principal da formação dessas trajetórias, pois teria dado suporte ao etanol brasileiro mesmo quando esse não era considerado competitivo em relação à gasolina.

O balanço fóssil é um dos mais importantes parâmetros para as energias alternativas. Muitos estudos não diferenciam a matéria-prima usada e chegam à conclusão de que o etanol não possui um bom balanço fóssil. No entanto, não consideram que o balanço energético do etanol a partir do milho é totalmente diferente do etanol a partir da cana. A matéria-prima usada no Brasil possui um balanço quase oito vezes melhor do que o americano por conta do menor uso de fertilizantes e do fato de as propriedades aproveitarem o bagaço na geração de energia elétrica (GOLDEMBERG e GUARDABASSI, 2009).

Outra importante preocupação seria a expansão da cultura para áreas da floresta Amazônica, mas, como mostram os estudos de Ferreira Filho e Horridge (2011), os principais plantios de cana- -de-açúcar estão localizados a mais de 2 mil quilômetros da floresta Amazônica, sendo impossível um efeito direto entre plantio de cana e devastação da Amazônia, por esta abordagem. A maioria da cana-de-açúcar é produzida em São Paulo, e neste estado em que quase não existe mais terra ociosa, a cana não poderia impactar diretamente nos desmatamentos da Amazônia. Entretanto, existe a possibilidade de a cana-de-açúcar causar indiretamente a devastação da floresta. Por isso, os efeitos são avaliados pelo uso indireto da terra. Nessa abordagem existe a possibilidade de a cana prejudicar a floresta pelo efeito indireto: as pastagens são expulsas de São Paulo para dar lugar à cana e vão para a fronteira agrícola, desmatando a floresta (FERREIRA FILHO e HORRIDGE, 2011).

A respeito desse efeito, o citado trabalho, baseado em um modelo de equilíbrio geral computável e matrizes de transição, encontrou que, para 2020, no cenário base, ter-se-ia aumento de $14 \%$ na produção de cana, com elevação de $8 \%$ na área plantada 7 . Um hectare de expansão da cana seria responsável por apenas 0,08 hectare de novas áreas (que é a proxy que o estudo usa para desmatamento). Considerando aumentos de produtividade, o impacto no desmatamento e no plantio de outras culturas seria ainda menor do que os dos parâmetros encontrados no estudo.

\footnotetext{
7 O fato de o aumento da produção ser maior do que o da área plantada não é devido ao aumento de produtividade, mas, sim, devido à realocação da produção de áreas menos produtivas para as mais produtivas.
} 


\section{Revisão de literatura: modelos de estimativa da demanda por combustíveis}

Os modelos de demanda por combustível seguem a teoria do consumidor tradicional, na qual a demanda por um produto depende do seu preço, da renda, dos preços dos bens substitutos e complementares, assim como das preferências individuais. Muitos dos estudos anteriores sobre a demanda por combustíveis usam apenas o preço do produto e uma proxy para renda, a exemplo dos estudos de Ramanathan (1999), Cheung e Thomson (2004) e Rodríguez (2006).

A gama de estudos sobre a demanda de combustíveis abarca diversos métodos econométricos. O estudo de Dahl e Sterner (1991) faz uma comparação entre os diferentes trabalhos sobre as elasticidades da demanda por gasolina. Os pesquisadores têm uma amostra de mais de uma centena de estudos e os classificam por periodicidade dos dados e pelas especificações dos modelos. Partindo de funções que estimam a demanda por gasolina $(\mathrm{G})$ em função apenas do seu preço (P) e da renda $(\mathrm{Y})$ :

$$
\mathrm{G}=\mathrm{f}(\mathrm{P}, \mathrm{Y})
$$

Chegando a modelos que incluem variáveis de estoque (V) e características sobre a frota (C) para estimar a demanda pelo combustível. A função demanda por gasolina seria, então, dada por:

$$
\mathrm{G}=\mathrm{f}(\mathrm{P}, \mathrm{Y}, \mathrm{V}, \mathrm{C})
$$

Considerando quaisquer das especificações, foram encontradas elasticidades-preço da demanda por gasolina entre $-0,12$ e $-0,44$ no curto prazo, e $-0,23$ e $-1,05$ no longo prazo. As elasticidades-renda variam entre 0,14 e 0,58 no curto prazo, e 0,68 e 1,31 no longo prazo (DAHL e STERNER, 1991).

Outro importante survey sobre a demanda por combustíveis é o artigo de Espey (1998). Utilizando meta análise, o artigo traz quais seriam as variáveis que explicam as diferenças nas elasticidades-preço e renda da demanda por gasolina. São usados trabalhos publicados entre 1966 e 1997 e que cobrem o período que vai de 1929 a 1993. O estudo mostrou que características do veículo como a eficiência dos motores produzem diferenças significativas nas elasticidades, reduzindo-as no longo prazo. Entretanto, as diferentes especificações (linear, log-linear ou modelos indiretos ${ }^{8}$ ) não mostraram diferenças significativas. Os modelos estáticos resultaram em maiores elasticidades de curto prazo e menores no longo prazo, sendo os resultados significativos. As diferenças na forma como é especificado o consumo de gasolina (per capita, por domicílio, por estado) não mostraram diferenças significativas.

O trabalho de Ramanathan (1999) estimou a demanda por gasolina na Índia, no período de 1972 a 1994, utilizando métodos de cointegração em séries temporais, com a renda e os preços da gasolina como variáveis explicativas. Cheung e Thomson (2004) fizeram estudo semelhante para a China no período de 1980 a 1999. Ambos os estudos concluíram que a gasolina é inelástica a preço no curto prazo com parâmetros próximos a -0,20. Em relação à elasticidade-renda, os estudos divergem, sendo que, no estudo de Cheung e Thomson (2004), a elasticidade-renda é maior no curto prazo do que no longo prazo. Ambos utilizaram apenas o preço da gasolina e proxies para renda como variáveis explicativas.

Nappo (2007), interessando em avaliar a influência da entrada dos carros flex-fuel na demanda por gasolina no Brasil, utilizou os métodos de cointegração em séries mensais de 1994 a 2006. As variáveis utilizadas para explicar o consumo da gasolina foram o seu preço, o preço do álcool, o PIB como proxy da renda, uma variável de tendência e uma dummy de inclinação associada ao preço da gasolina a partir de 2003 . O preço do etanol não foi significativo, mas a binária de inclinação foi significativa e com o sinal esperado, mostrando que a entrada dos carros flex-fuel tornou a demanda por gasolina mais elástica no

\footnotetext{
8 Especificações indiretas no trabalho de Espey (1998) são aquelas que dependem de outras equações além da demanda. Ou seja, incluir outras equações como a oferta do combustível, apesar de ser mais preciso do ponto de vista econométrico, não traz resultados significativamente diferentes.
} 
período pós-2003 quando comparada ao período anterior. As elasticidades-preço de curto prazo encontradas pelo autor foram de $-0,20$ (pré-flex) e -0,33 (pós-flex).

Souza (2010) analisa a demanda por etanol e gasolina com séries mensais com dados que vão de 2001 a 2009 para o Brasil, seguindo linha semelhante ao de Nappo (2007), com o avanço de usar dados em painel. Para a demanda por etanol, o autor utiliza os preços da gasolina, o preço do etanol, o consumo de energia (proxy da renda), a frota de carros flex e movidos a álcool e dummies mensais, anuais e de faixa de preços relativos ${ }^{9}$. $\mathrm{O}$ estudo faz uma análise em painel em dois estágios controlando a endogeneidade das demandas (álcool e gasolina) por vários instrumentos, sendo que os que mostraram melhores resultados foram os preços do etanol nos mercados vizinhos. No entanto, nada é mencionado com relação à possibilidade de dependência na cross section dos dados em painel utilizados.

Serigati, Correia e Pedrosa (2010) estimaram as equações de demanda por etanol, açúcar e a oferta de álcool simultaneamente por 3SLS ${ }^{10}$ para o Brasil. Além das variáveis usuais (preço e renda), foram usadas também o estoque de carros flex e álcool na demanda por etanol e dummies interadas para o preço da gasolina e quantidade de álcool na equação demanda por álcool. Os dados dos autores foram agregados para o Brasil inteiro com periodicidade anual, com 94 observações. Os resultados mostraram que o etanol é elástico a preço com elasticidade por volta de 1,2 em módulo no período pré-flex, e de 2,0 no período pós-flex. A elasticidade cruzada também aumentou, passando de 1,2 para 2,0 nos períodos mencionados.

Randow, Fontes e Carminati (2010) estimaram a demanda de longo prazo por etanol

9 Souza (2010) separa os estados conforme a média de preços relativos e os trata de forma diferente. O pressuposto é que estados com preços relativos distantes do limite dos $70 \%$ respondessem menos às mudanças de preços, uma vez que pequenas mudanças nesses valores não fariam o consumidor mudar de zona (da zona vantajosa para consumo de etanol para desvantajosa, e vice-versa).

10 Mínimos Quadrados em Três Estágios. usando cointegração em séries temporais. As variáveis para estimar o consumo por etanol foram o seu preço, o preço da gasolina e o PIB como proxy da renda. Os resultados encontrados indicam demanda altamente elástica a preço e ao preço cruzado no longo prazo (-11,26 e 12,79, respectivamente), e baixa elasticidade-renda $(0,46)$. Também usando métodos de cointegração em séries temporais, Farina et al. (2010) analisam o período de julho de 2001 a agosto de 2009 e encontra elasticidade-preço de curto prazo para o Brasil de -1,23 e elasticidade cruzada de 1,45.

Recentemente, o estudo de Santos (2012) mostrou ser uma importante contribuição à literatura. Esse estudo usa dados em painel em bases trimestrais e chega a uma elasticidade-preço de $-1,25$ no curto prazo e $-8,45$ no longo prazo. $\mathrm{O}$ autor sugere precaução com os resultados de longo prazo por entender que tal elasticidade esteja superestimada.

\section{O modelo proposto e descrição dos dados}

O presente estudo utiliza um painel balanceado, ou seja, as variáveis estão disponíveis para todos os períodos e estados. O índice $i$ diz respeito aos 26 estados brasileiros e ao Distrito Federal e, portanto, varia de 1 a 27 . O índice $t$ se refere à dimensão temporal do painel e vai de julho de 2001 até julho de 2011, variando de 1 a 121 . Sendo assim, o painel tem 3.267 observações (i x t).

As variáveis utilizadas são a quantidade de etanol hidratado vendida nos postos de abastecimento (Qeta) fornecida pela Agência Nacional do Petróleo, Gás Natural e Biocombustíveis (ANP). Os preços do etanol $(\mathbf{P e})$ e da gasolina $(\mathbf{P g})$ correspondem à média mensal dos preços ao consumidor do etanol hidratado/gasolina-C ponderada pelas quantidades vendidas em cada posto.

A variável Renda refere-se aos gastos totais em energia elétrica (proxy para renda) por estado. Vale lembrar que esses dados são disponibilizados para as regiões do Brasil, sendo imposto um efeito fixo por região. A correlação entre o PIB per 
Tabela 2. Estatística descritiva

\begin{tabular}{lccccc}
\hline \multicolumn{1}{c}{ Variável } & Obs & Mín & Max & Média & Desvio Padrão \\
\hline Qeta (mil litros) & 3267 & 0,10 & 3005,50 & 996,66 & 308,9 \\
Frota (mil carros) & 3267 & 9,00 & 16000,00 & 1395,38 & 2479,35 \\
Frete (R\$.Km) & 3267 & 120,45 & 7585,34 & 1586,29 & 1885,96 \\
Pe (R\$) & 3267 & 0,75 & 2,87 & 1,66 & 0,35 \\
$\operatorname{Pg}(\mathrm{R} \$)$ & 3267 & 1,42 & 3,22 & 2,38 & 0,34 \\
\hline
\end{tabular}

Fonte: Elaboração própria.

capita e o gasto de energia elétrica foi de $0,894^{11}$, indicando que se trata de uma boa proxy. Os dados estão disponíveis no sítio da Eletrobrás.

A Frota corresponde ao somatório da frota movida a álcool com a frota flex-fuel. Por conta da tendência a superestimar os reais valores para a frota circulante, ao invés de usar os dados do Denatran, foi construída a frota circulante a partir do ano-base de 1990, e a partir daí foram somadas as vendas de veículos fornecidas pela Anfavea, respeitando a função de sucateamento usada por Souza (2010) e Serigati, Correia e Perosa (2010), ambas com os parâmetros contidos em MCT $(2006)^{12}$.

O Frete corresponde aos custos com transporte do etanol. Como não existe base mensal de custo de frete para todos os estados na abrangência temporal do estudo (2001 a 2011), a variável foi construída com base nos seus dois determinantes principais (distância e preço do diesel). A distância foi calculada de acordo com o estado mais próximo com excedente na produção de etanol. Na Tabela 2 tem-se a descrição dos dados a serem utilizados na análise empírica.

Em modelos de demanda de combustíveis para o Brasil, após a entrada do flex-fuel em 2003, se tornou imprescindível considerar que os combustíveis gasolina e etanol são substitutos para quase metade da frota de veículos leves. Por isso,

11 A correlação entre as duas variáveis foi feita a partir das séries anuais do PIB e do consumo de energia elétrica fornecidos pelo IBGE e Eletrobrás, respectivamente, sendo que a série vai de 1952 a 2009.

12 A função é dada por $S(t)=\exp \{-\exp [(a+b(t)]\}$, em que $\mathrm{S}(\mathrm{t})$ é a quantidade de carros sucateada no tempo $\mathrm{t}$ (idade do veículo). Os parâmetros fornecidos por MCT (2006) são $a=1,798$ e $b=-0,137$. o modelo proposto possui as seguintes variáveis explicativas para demanda por etanol: preço, renda, preço do substituto (gasolina), estoque de veículos e uma variável de controle da endogeneidade entre preço e quantidade, o custo com frete.

O frete é incluído como instrumento do preço, mas também é tratado como variável exógena ${ }^{13}$ em algumas especificações. Segue o modelo ${ }^{14}$ básico de demanda para o etanol a ser estimado:

$$
\begin{aligned}
& \text { Qeta }_{i t}=\beta_{0}+\beta_{1} \cdot \text { Pe }_{i t}+\beta_{2} \cdot P_{i t}+\beta_{3} \cdot \text { Re nda }_{i t}+ \\
& +\beta_{4} \cdot \text { Frota }_{i t}+\beta_{5} \cdot \text { Frete }_{i t}+\varepsilon_{i t}
\end{aligned}
$$

Além do modelo básico representado pela Equação (3), inclui-se variável dummy $\left(\mathrm{D}_{1}\right)$ associada ao preço do etanol para verificar se existe mudança nas elasticidades-preço da demanda de curto e de longo prazo nos períodos pré e pós-flex-fuel. Outra dummy $\left(\mathrm{D}_{2}\right)$ é associada ao preço da gasolina, referente ao mesmo período que $\mathrm{D}_{1}$. Por fim, tem-se uma terceira binária $\left(D_{3}\right)$, referente às mudanças na elasticidade-renda. São adicionadas

13 Como sugere Choi (2002), as variáveis instrumentais podem ser incluídas como exógenas no modelo graças à garantia de propriedades assintóticas dos painéis. Ou seja, o teorema do limite central é válido por conta do aumento da amostra que ocorre nos painéis. Tratamento semelhante não pode ser aplicado às séries temporais.

14 Além das variáveis utilizadas, estudos como Schunemann (2007) utilizam a eficiência dos carros como variável explicativa. Porém, considera-se que, assim como a eficiência dos carros aumentou, outros fatores andaram na contramão da eficiência, os congestionamentos, por exemplo, não sendo necessário incluir tal variável. Outra explicação para não inclusão da eficiência dos carros como variável explicativa é que a eficiência mudaria lentamente ao longo do tempo, sendo esse efeito captado pelas dummies anuais. 
também dummies anuais e mensais ${ }^{15}$ com o intuito de retirar possíveis efeitos sazonais. As dummies têm valor igual a 1 no período pós agosto de 2006 e igual a zero em períodos anteriores a agosto de 2006. A escolha por 2006 e não 2003 é justificada por conta de a frota flex ser muito incipiente imediatamente após o lançamento dos carros flex. $\mathrm{O}$ marco em agosto de 2006 foi escolhido por ser o mês em que as vendas de carros flex superam a de carros movidos a gasolina.

Sobre a influência dos preços externos do açúcar, do petróleo ou do etanol nas regressões, vale lembrar que estas não são incluídas porque elas são iguais para todo o painel e já são captadas pelas dummies anuais e mensais. No caso de séries temporais, tais variáveis deveriam ser incluídas.

\section{Metodologia econométrica}

Nesta seção, são apresentados breves esclarecimentos sobre alguns dos testes e estimadores usados no trabalho, dando prioridade aos menos conhecidos.

\subsection{Testes usados}

O Fator de Inflação da Variância (FIV) é usado para medir se existem problemas de multicolinearidade nas estimativas. A ideia do teste é regredir cada variável explicativa como se fosse a variável dependente e, a partir dessa nova regressão, é calculado o inverso de $\left(1-\mathrm{R}_{\mathrm{i}}^{2}\right)$; se esse valor for maior que 10, diz-se que a variável sofre de forte multicolinearidade (Greene, 2000).

O teste de Wald Modificado tem poder aumentado em relação ao tradicional, principalmente em amostras reduzidas, ao violar o pressuposto básico de que os erros sejam independentes e normalmente distribuídos. Por isso, o teste é particularmente importante no caso das estimativas a serem realizadas para as regiões. A

15 As dummies mensais e anuais possuem valor 1 para o mês/ ano em questão e igual a zero nos demais. A dummy para 2001 (A2001), por exemplo, possui valor 1 em 2001 e 0 nos demais anos. hipótese nula do teste é que a variância dos erros é homocedástica.

O teste de Hausman (1978) compara dois modelos distintos com a hipótese nula de que a diferença entre os estimadores dos dois modelos não é sistemática (Ho: $\left.\beta_{1}-\beta_{2}=0\right)$. Se Ho é aceita, o modelo de efeitos aleatórios é adotado; se ela é rejeitada, adota-se o modelo de efeitos fixos. $\mathrm{O}$ modelo de efeitos fixos é consistente mesmo na presença de efeitos aleatórios.

A literatura de séries temporais para detectar e tratar o problema das raízes unitárias é bastante vasta. Porém, a literatura de painéis ainda está avançando nesta direção com o aumento da dimensão temporal dos dados em painel e maior probabilidade de ocorrências de raízes unitárias nos painéis, sendo que os testes e estimadores vêm avançando para lidar com esses problemas de presença de raízes unitárias. Mas por que usar novos testes ao invés de simplesmente usar os conhecidos testes Dickey-Fuller (DF), Dickey-Fuller Aumentado (ADF) e Phillips-Perron (PP) para séries temporais? A resposta parece estar no fato de que os novos testes possuem maior potencial para detectar tais problemas, pois aumentam consideravelmente o tamanho da amostra ao considerar também a dimensão cross section. Por isso, usa-se nesse artigo o teste de Hadri (2000) para verificar a presença de raízes unitárias.

Outro problema frequente nos estudos econômicos em painéis é a possível dependência na dimensão cross section da amostra. No caso do presente estudo, é complicado supor que os preços de estados vizinhos não possuam algum tipo de influência mútua. Entretanto, a maioria dos estimadores pressupõe que não existe dependência entre as cross section e, caso estes sejam usados, corre-se o risco de estarem sendo estimadas regressões espúrias. Por isso, para detectar tal dependência é usado o teste de Pesaran (2004), cuja hipótese nula é de independência na dimensão cross section. Uma das soluções possíveis para controlar a dependência dentro do painel (raízes unitárias) e na cross section é usar os estimadores Dynamic Ordinary Least Squares (DOLS) ou o Fully Modified Ordinary Least Squares (FMOLS), desde que as séries cointegrem. 
Para verificar a hipótese de cointegração, utiliza-se o teste de Westerlund (2007).

Os testes mais antigos para cointegração, como o teste de Kao (1999) e Pedroni (1995), exigem que os parâmetros de curto prazo sejam iguais aos parâmetros de longo prazo para que seja rejeitada a hipótese nula de ausência de cointegração. Já o teste de Westerlund (2007) relaxa essa restrição. Mesmo assim, existe a necessidade de que as variáveis sejam integradas de ordem 1 , por isso, no caso da frota (para o Brasil), usa-se a variável em primeira diferença, uma vez que ela torna-se estacionária em segunda diferença. $\mathrm{O}$ mesmo procedimento é usado nas séries para as regiões, ou seja, respeita-se a estacionariedade de cada série para que seja feito o teste ${ }^{16}$. O número de lags do teste é escolhido automaticamente pelo critério de $\mathrm{AIC}^{17}$. O teste reporta 4 estatísticas distintas: $\mathrm{Ga}, \mathrm{Gt}, \mathrm{Pa}$ e Pt. O primeiro par são as estatísticas referentes à cointegração no grupo, e consideram que o painel é inteiramente cointegrado e que o fator de cointegração é o mesmo para todo o painel. Pa e Pt são referentes à cointegração no painel, e consideram a existência de pelo menos uma seção cointegrada que, no caso desse estudo, existe pelo menos um estado cointegrado.

\subsection{Estimadores}

Baseados nos resultados dos testes econométricos, foram escolhidos o GLSHA para as estimativas de curto prazo e o DOLS para as de longo prazo. Por isso, serão explicitados alguns comentários sobre os dois estimadores.

16 Vale lembrar que nem todas as variáveis precisam ser integradas de mesma ordem para que elas cointegrem. Ou seja, variáveis de ordens diferentes podem cointegrar e isso ocorre, geralmente, em ordem superior. Ou seja, variáveis que possuem resíduos de ordem 1 e 2, geralmente cointegram em ordem 2. Assim, não necessariamente as séries precisam ser de mesma ordem de integração para que exista cointegração (HAYASHI, 2000).

$17 \mathrm{O}$ teste escolhe automaticamente o número de lags pelo critério de Akaike, sendo necessário apenas especificar o número máximo pela regra de "bolso" sugerida por Westerlund (2007), $\operatorname{lag}_{\max }=4 .(\mathrm{T} / 100)^{2 / 9}$, em que T é o número de períodos da série.
Para o curto prazo, o estimador pooled OLS não poderia ter sido usado por conta de este pressupor homocedasticidade, não dependência na dimensão cross section, e séries estacionárias, características que não estão presentes nas séries usadas. Outros estimadores, como o estimador de Prais-Winsten (PSCE), por exemplo, também levam em conta a correlação serial e temporal (dentro do painel) ${ }^{18} \mathrm{e}$, teoricamente, seriam apropriados às estimativas de curto prazo, assim como o GLS com correção para erros AR(1) e dependência na cross section.

Para a relação de longo prazo, diante da existência de cointegração, pode-se usar o estimador DOLS, proposto por Kao e Chiang (2000), para estimar as relações de longo prazo para a demanda por etanol ${ }^{19}$. O estimador exige que as variáveis sejam inseridas pressupondo que os seus erros são I(1). No caso do presente estudo, como existem algumas variáveis que são I(2), estas foram incluídas em primeira diferença no modelo para que seus erros fossem I(1), como a construção do estimador exige.

A escolha do estimador DOLS leva em consideração Kao (1999), que compara a eficiência dos estimadores OLS, FMOLS e DOLS e conclui que o estimador OLS tem um viés que não é desprezível para pequenas amostras e presença de heterocedasticidade. O estimador FMOLS não consegue melhorar muito esse viés, sendo então o estimador DOLS a escolha mais promissora para o caso em que são encontrados painéis com dependência na dimensão cross section, não estacionários e cointegrados. A estatística do estimador parte também de um modelo padrão:

$$
Y_{i t}=\alpha_{i}+\beta^{\prime} X_{i t}+v_{i t}
$$

\footnotetext{
18 Mais detalhes em Prais e Winsten (1954).

19 Mais detalhes sobre a aplicação do estimador DOLS às relações de longo prazo podem ser encontradas em Mark e Sul (2003) e Saeb (2004).
} 
Tabela 3. Testes de Hadri para variáveis logaritmizadas

\begin{tabular}{ccccc}
\hline Variável & Hadri & CT & CT, MG & CT, MG, DEP \\
\hline Pe & $246,448^{* * *}$ & $91,95^{* * *}$ & $74,97^{* * *}$ & $68,66^{* * *}$ \\
Pg & $317,69^{* * *}$ & $214,80^{* * *}$ & $118,82^{* * *}$ & $100,90^{* * *}$ \\
Qeta & $364,70^{* * *}$ & $102,66^{* * *}$ & $106,74^{* * *}$ & $106,74^{* * *}$ \\
Renda & $380,74^{* * *}$ & $35,60^{* * *}$ & $77,07^{* * *}$ & $77,07^{* * *}$ \\
Frota & $376,35^{* * *}$ & $355,90^{* * *}$ & $306,59^{* * *}$ & $306,59^{* * *}$ \\
Frete & $349,40^{* * *}$ & $258,55^{* * *}$ & $146,45^{* * *}$ & $146,45^{* * *}$ \\
Ho & & Os painéis são estacionários & \\
\hline
\end{tabular}

Nota: $\left.\left({ }^{*}\right),{ }^{* *}\right)$ e $\left({ }^{* * *}\right)$ indicam o grau de significância estatística, respectivamente, de $10 \%, 5 \%$ e $1 \%$. O teste segue uma distribuição normal.

Fonte: Elaboração própria.

Adicionando a correção ${ }^{20}$ (parte em negrito na equação a seguir), o modelo é transformado para:

$$
Y_{i t}=\alpha_{i}+\beta^{\prime} X_{i t}+v_{i t}+\sum_{k=k i}^{k 1} Y_{i k} \Delta X_{i t-k}+v_{i t}
$$

O coeficiente $\beta_{\mathrm{DOLS}}$ é, então, dado por:

$$
\beta_{\text {Dols }}=N^{-1} \sum_{i=1}^{N}\left(\sum_{t=1}^{\top} Z_{i t} Z_{i t}^{\prime}\right)^{-1}\left(\sum_{t=1}^{\top} Z_{i t} Y_{i t}^{\prime}\right)
$$

Em que $\mathbf{Z}_{\mathrm{it}}$ é um vetor que representa as diferenças entre $X_{i t}$ e a média do painel $\left(X_{i}\right)$ na primeira coluna, e nas demais colunas os regressores em diferença $\left(\Delta X_{i t-k}, \ldots, \Delta X_{i t+k}\right)$.

\section{Resultados}

Foram feitos os testes econométricos pertinentes à literatura de painéis, no intuito de conhecer as especificidades das séries e, assim, conseguir determinar quais os estimadores indicados. Após os testes, são apresentados os resultados obtidos. Esta seção está separada primeiramente em testes e resultados para o Brasil e, após isso, testes e resultados para as regiões brasileiras.

A ideia do vetor de correção em painéis é a mesma utilizada nas metodologias Vector Error-Correction (VEC) para séries temporais.

\subsection{Resultados para o Brasil}

\subsubsection{Testes Econométricos}

Com todo o resto constante, quanto maior a FIV, maior a multicolinearidade. Nas séries usadas, a multicolinearidade não é um problema, uma vez que o FIV de nenhuma variável foi superior a 2,04 e o FIV médio da regressão foi de 1,4421. Os testes de Wald Modificado e de Hausman rejeitaram a $1 \%$ de significância as respectivas hipóteses nulas, indicando que as séries são heterocedásticas e que o painel em efeitos fixos é adequado ao estudo. A variável "frete" foi incluída como um controle no caso dos modelos de efeitos aleatórios para efeito de comparação.

Como descrito na metodologia, com o aumento da dimensão temporal dos painéis, a econometria de dados em painel começa a ter que lidar com um problema típico das séries temporais, a presença de raízes unitárias (MÁTYÁS e SEVESTRE, 2008). Para verificar a estacionariedade dos painéis, foi usado o teste de Hadri (2000), que possui como hipótese nula a estacionariedade de todos os painéis. O teste foi repetido com a inclusão de tendência temporal (CT), a retirada das médias dos grupos (MG) e permitindo dependência ao longo da cross section (DEP). Os resultados podem ser verificados na Tabela 3.

\footnotetext{
21 A multicolinearidade é um problema sério se o FIV for maior que 10.
} 
Como mostra a Tabela 3, a hipótese de que os painéis são estacionários foi fortemente rejeitada para todas as variáveis. Como alternativa ao problema da estacionariedade no painel, assim como é feito nas séries temporais, são usadas estimativas em diferença, pois regressões espúrias podem aparecer se a natureza não estacionária das séries não for levada em consideração. Com isso, foi corrigido tal problema para todas as variáveis, exceto para a frota, que se tornou estacionária em segunda diferença.

A dependência na cross section pode gerar regressões espúrias para a maioria dos estimadores e esse é um problema que raramente é testado nos trabalhos empíricos usando dados em painel. Tentando avançar nesse sentido, foi usado o teste de Pesaran (2004) com a hipótese nula de que não existe dependência entre as cross sections, conforme Tabela 4.

A hipótese nula foi fortemente rejeitada, indicando dependência entre as cross sections. A Tabela 4 mostra também que as estimativas em diferença não corrigem tal problema conforme já indicava
Mátýas e Sevestre (2008). Ou seja, mesmo usando estimadores em primeira diferença é corrigido apenas o problema da dependência temporal e não o da dependência na cross section.

Diante dos resultados, são possíveis algumas alternativas para contornar o problema. Uma delas é usar as estimativas em primeira diferença (para correção da dependência temporal) em conjunto com estimadores que levem em conta o problema da dependência nas cross sections. As escolhas aqui são o estimador GLS com correção para heterocedasticidade e dependência na cross section para o curto prazo e o estimador DOLS para o longo prazo. Entretanto, para usar o estimador DOLS é necessário verificar se as séries realmente cointegram usando o Teste de Westerlund (2007). Os resultados estão na Tabela 5 .

Em todas as quatro estatísticas do teste a hipótese nula de ausência de cointegração foi fortemente rejeitada. Por isso, a conclusão do teste é que existe relação de longo prazo estável entre as variáveis, ou seja, elas realmente cointegram. E, por isso, é viável o uso do estimador DOLS.

Tabela 4. Teste para dependência na cross section de Pesaran (2004)

\begin{tabular}{ccc}
\hline Variável & Pesaran CD & Primeira Diferença \\
\hline Pe & $200,60^{* * *}$ & $135,06^{* * *}$ \\
Pg & $203,99^{* * *}$ & $108,73^{* * *}$ \\
Qeta & $165,80^{* * *}$ & $113,61^{* * *}$ \\
Renda & $195,72^{* * *}$ & $86,44^{* * *}$ \\
Frota & $206,08^{* * *}$ & $205,23^{* * *}$ \\
Frete & $205,25^{* * *}$ & $189,62^{* * *}$ \\
Ho & & Independência na cross section \\
\hline
\end{tabular}

Nota: $\left.\left({ }^{*}\right),{ }^{* *}\right)$ e $\left({ }^{* *}\right)$ indicam o grau de significância estatística, respectivamente, $10 \%, 5 \%$ e $1 \%$. O teste segue uma distribuição do tipo chi-quadrada. Fonte: Elaboração própria.

Tabela 5. Teste de Westerlund (2007) ${ }^{\mathrm{a}}$ para cointegração

\begin{tabular}{cc}
\hline Westlund (2007) & Z \\
\hline Gt & $-3,15^{* * *}$ \\
Ga & $-18,07^{* * *}$ \\
Pt & $-17,97^{* * *}$ \\
Pa & $-20,03^{* * *}$ \\
Ho & Ausência de cointegração \\
\hline
\end{tabular}

Nota: $\left({ }^{*}\right),\left({ }^{* *}\right)$ e $\left(^{* * *}\right)$ indicam o grau de significância estatística, respectivamente, de $10 \%, 5 \%$ e $1 \%$. O teste segue uma distribuição normal. a) Mais explicações sobre as estatísticas do teste são encontradas na parte da metodologia econométrica e em Westerlund (2007).

Fonte: Elaboração própria. 


\subsubsection{Resultados das estimativas}

Os estimadores que foram julgados como os mais adequados para o estudo foram o GLS com correção para heterocedasticidade e autocorrelação do tipo $A R(1)$, que aqui será tratado como GLSHA, e o DOLS. Mesmo assim, outros estimadores, como o GLS com efeitos fixos e o GLS com efeitos aleatórios, serão apresentados nos resultados para efeitos de comparação.

Vale lembrar que os resultados da Tabela 6 a seguir são referentes à equação sem as dummies interadas, mas com as dummies anuais e mensais.

As variáveis tiveram os resultados esperados: o preço do etanol foi negativamente relacionado com a quantidade, e o preço do substituto (gasolina), a renda e a frota respondem positivamente à quantidade demandada. Os resultados foram estatisticamente significativos a $1 \%$ de significância e mostraram robustez através dos diferentes estimadores para o curto prazo. Frete foi a única variável cujo coeficiente apareceu com sinal diferente do esperado em duas especificações, enquanto esperava-se um sinal negativo para a variável, ela apresentou sinal positivo nos modelos (2) e (3), porém, não se pode dizer que os resultados são estatisticamente diferentes de zero. Usando o modelo DOLS (5), o frete apresentou o sinal esperado (negativo) e o resultado foi estatisticamente significativo a $1 \%$. $O \mathrm{R}^{2}$ da estimativa DOLS foi, como esperado, mais elevado por conta de incluir no vetor de correção de erros também variáveis defasadas.

Dos modelos (1) ao (4), o preço do etanol mostrou elasticidade por volta de 1,5 , com coeficiente altamente significativo em todas as especificações. No modelo (5), o resultado mostra maior elasticidade $(3,3)$, o que era esperado por se tratar de uma relação de longo prazo. Outros estudos, como o de Gómez e Tamarit (2011), encontraram diferenças semelhantes na comparação dos estimadores GLS em comparação com o DOLS.

$O$ coeficiente da renda teve resultados que vão de 0,42 no modelo (3) a 0,49 nos modelos (1), (2) e (4), sendo todos esses resultados para o curto prazo, mostrando que o etanol, de forma agregada, pode ser considerado como um produto normal $(0<\mathrm{Er}<1)$ quanto à elasticidade-renda da demanda. No resultado para o longo prazo, a renda mostrou-se menos inelástica, com coeficiente próximo de 0,91 no estimador DOLS; entretanto, ainda inelástico a variações na renda. Todos os resultados para os coeficientes estimados para a variável renda da Tabela 6 foram significativos a $1 \%$ de significância.

A elasticidade-preço cruzada do etanol, ou seja, o parâmetro atribuído ao preço da gasolina, foi significativo e positivo em todos os estimadores da tabela, com resultados por volta de 0,81 no

Tabela 6. Parâmetros estimados para o Brasil - estimativa sem as dummies

\begin{tabular}{|c|c|c|c|c|c|}
\hline \multirow{2}{*}{ Variável } & \multicolumn{4}{|c|}{ Curto Prazo } & \multirow{2}{*}{$\frac{\text { Longo Prazo }}{D O L S(5)}$} \\
\hline & $F E(1)$ & $R E(2)$ & GLSHA(3) & $I V(4)$ & \\
\hline $\mathrm{Pe}$ & $-1,53^{* * *}$ & $-1,54^{* * *}$ & $-1,42^{* * *}$ & $-1,53^{* * *}$ & $-3,30 * * *$ \\
\hline $\mathrm{Pg}$ & $0,86^{* * *}$ & $0,81^{* * *}$ & $0,73^{* * *}$ & $0,86^{* * *}$ & $2,82^{* * *}$ \\
\hline Renda & $0,49^{* * *}$ & $0,49^{* * *}$ & $0,42^{* * *}$ & $0,49 * * *$ & $0,91^{* * *}$ \\
\hline Frota & $47,85^{* * *}$ & $47,39 * * *$ & $44,21^{* * *}$ & $47,81^{* * *}$ & $25,51^{* * *}$ \\
\hline Frete & - & 0,12 & 0,12 & - & $-0,54^{* * *}$ \\
\hline Const. & $-0,04^{* * *}$ & $-0,04^{* * *}$ & $-0,04^{* * *}$ & $-0,04$ & - \\
\hline $\mathrm{R}^{2}$ & 0,31 & 0,31 & 0,31 & 0,31 & 0,88 \\
\hline $\mathrm{N}$ & 3101 & 3101 & 3101 & 3101 & 3120 \\
\hline
\end{tabular}

Notas: $\left({ }^{*}\right),(* *)$ e $\left(^{* * *}\right)$ indicam o grau de significância estatística, respectivamente, de 10\%,5\% e 1\%. (1) Modelo GLS com efeitos fixos e sem a variável "frete". (2) Modelo GLS com efeitos aleatórios. (3) Modelo GLS com correção para heterocedasticidade e para os erros autocorrelacionados. (4) Modelo com variáveis instrumentais, instrumentalizando o preço pelo frete. (5) Modelo DOLS - Dynamic Ordinary Least Squares. Todos os modelos foram estimados com dummies anuais e mensais com a finalidade de retirar o efeito fixo do ano e dos meses na estimativa. 
curto prazo e de 2,82 no longo prazo. Os resultados da Tabela 6 também indicam que a demanda por etanol varia mais em relação ao seu próprio preço do que em relação ao preço da gasolina e à renda, o que é um resultado interessante no auxílio à prescrição de políticas públicas voltadas para o setor.

Vale lembrar que a inclusão da variável que é tipicamente relacionada à oferta para controlar a endogeneidade do preço pode ser feita como variável instrumental, como foi feito no modelo (4). Adicionalmente, seguindo a sugestão de Choi (2002), pode-se tratar o instrumento como variável endógena, como foi realizado nos modelos (2), (3), e (5). O autor ainda alerta que essa opção pode ser feita para dados em painéis por conta do aumento do tamanho da amostra e possibilidade de aplicação do teorema do limite central, sendo que o mesmo procedimento não é válido para as séries temporais.

O modelo também foi estimado com dummies interadas a $P e, P g$ e Renda para verificar as mudanças provocadas pela entrada dos carros flex-fuel no mercado. Portanto, a diferença da Tabela 6 para a Tabela 7 está justamente na inclusão das dummies interadas, permitindo que existam diferentes elasticidades entre os períodos.

Os resultados indicam, assim como o trabalho de Serigati, Correia e Pedrosa (2010), que ocorreu um aumento nas elasticidades-preço e elasticidade-cruzada do etanol no curto prazo, resultado esperado por conta da possibilidade de escolha entre etanol e gasolina que os consumidores tiveram após o advento dos carros flex-fuel. O resultado é significativo a 1\% para as três dummies utilizadas. Esse resultado indica que os carros flex trouxeram maior possibilidade de arbitragem dos consumidores no combustível escolhido, o bem se tornou um pouco menos essencial pela possibilidade de substituição sem necessidade de troca do veículo. Por isso, os consumidores ficaram mais sensíveis aos preços no período mais recente, tanto na variação do próprio preço do etanol, quanto no preço do principal substituto (gasolina).

Independente de se tratar do cenário de curto ou de longo prazo, a demanda por etanol responde mais aos preços do etanol do que aos preços da gasolina. Mesmo que o resultado esperado seja esse, é necessário salientar que os desvios das séries de gasolina são menores do que os das séries de etanol, isso devido ao fato de a maior parte da gasolina distribuída no Brasil ser refinada pela Petrobrás e essa, por sua vez, suavizar os repasses das variações nos custos, o que não ocorre com os preços do etanol. As elasticidades-renda não tiveram mudanças significativas entre os dois períodos tanto no curto quanto no longo prazo. Mas, a elasticidade-renda de longo prazo foi quase o dobro da elasticidade-renda de curto prazo, passando de valores próximos a 0,50 para valores próximos a 1,00 .

Tabela 7. Elasticidades pré e pós-flex-fuel no Brasil

\begin{tabular}{|c|c|c|c|c|c|}
\hline \multirow[b]{2}{*}{ Elasticidades Pré-Flex } & \multicolumn{4}{|c|}{ Curto Prazo } & \multirow{2}{*}{$\begin{array}{c}\text { Longo Prazo } \\
\text { DOLS }\end{array}$} \\
\hline & $F E$ & $R E$ & GLSHA & $I V$ & \\
\hline $\mathrm{Ep}$ & $-1,11^{* * *}$ & $-1,11^{* * *}$ & $-0,96^{* * *}$ & $-1,06^{* * *}$ & $-3,41^{* * *}$ \\
\hline Ec & $0,63^{* * *}$ & $0,64^{* * *}$ & $0,58^{* * *}$ & $0,61^{* * *}$ & $2,87^{* * *}$ \\
\hline Er & $0,51^{* * *}$ & $0,51^{* * *}$ & $0,45^{* * *}$ & $0,51^{* * *}$ & $0,91^{* * *}$ \\
\hline Elasticidades Pós-Flex & $F E$ & $R E$ & GLSHA & $I V$ & DOLS \\
\hline Ep & $-2,13^{* * *}$ & $-2,13^{* * *}$ & $-2,13^{* * *}$ & $-2,09 * * *$ & $-2,48^{* * *}$ \\
\hline Ec & $1,23^{* * *}$ & $1,25^{* * *}$ & $1,27^{* * *}$ & $1,23^{* * *}$ & $2,07^{* * *}$ \\
\hline Er & $0,47 * * *$ & $0,47^{* * *}$ & $0,40^{* * *}$ & $0,46^{* * *}$ & $1,05^{* * *}$ \\
\hline
\end{tabular}

Nota: $\left({ }^{*}\right),\left({ }^{* *}\right)$ e $\left({ }^{* *}\right)$ indicam o grau de significância estatística, respectivamente, de $10 \%, 5 \%$ e $1 \%$. Vale ressaltar que o modelo foi estimado com todas as variáveis, mas foram reportadas apenas as variáveis de interesse aqui. O modelo foi estimado com as dummies (D1, D2 e D3), além das variáveis que já vinham sendo usadas (frota e frete, além da constante); só não foram reportados os valores para melhor visualização das diferenças nas elasticidades.

Fonte: Elaboração própria. 
Os aumentos das elasticidades-preço e cruzada do etanol no curto prazo com a entrada dos flex era esperado, mas os resultados de longo prazo, não. As duas elasticidades (preço e cruzada) foram reduzidas com a entrada dos flex no mercado. A explicação encontrada para o fenômeno foi que, devido à parte da variabilidade do consumo ser atrelada à uma escolha de longo prazo (escolha do combustível que o carro usará, uma vez que não se espera que os consumidores troquem de carro a todo momento), a passagem dessa escolha para o curto prazo (carros flex) aumentou a variabilidade em relação aos preços (gasolina e etanol) no curto prazo, mas a diminui no longo prazo.

\subsection{Resultados para as regiões}

Para mostrar as diferenças nos parâmetros entre as regiões, foram estimadas as elasticidades do período inteiro (modelo sem as dummies) para cada uma das cinco regiões. Com as estimativas por regiões se ganha em detalhamento, porém, perde-se em graus de liberdade. No entanto, como a amostra da região Sul é a menor delas (357 observações para o curto prazo), as propriedades assintóticas dos estimadores continuam garantidas. Como possivelmente algumas características das séries podem ter mudado com o redimensionamento das amostras, os testes precisaram ser feitos para cada subamostra.

\subsubsection{Testes econométricos}

Como na análise anterior, as séries não mostraram problemas de multicolinearidade pelo Fator de Inflação da Variância (FIV). Nenhuma região teve FIV médio maior que 1,60. O Teste de Wald Modificado indicou que as séries das regiões possuem problemas de heterocedasticidade, com exceção da região Sul para a qual não foi rejeitada a hipótese nula de homocedasticidade. No Teste de Hausman para especificação, as regiões Sul e Nordeste não rejeitaram a hipótese nula, indicando para o uso dos efeitos aleatórios.
Em relação à estacionariedade, o teste de Hadri (2000) mostrou que todas as regiões se comportaram de forma semelhante: as variáveis foram estacionárias em primeira diferença, com exceção das variáveis frete e frota que foram estacionárias apenas em segunda diferença.

Para testar se existe dependência na dimensão cross section, mais uma vez foi usado o Teste de Pesaran (2004) que, novamente, mostrou que em todas as variáveis se rejeita a $1 \%$ de significância a hipótese nula de independência na cross section.

O último teste, assim como feito nas estimativas para todo o Brasil, foi o teste para existência de cointegração de Westerlund (2007), e nas quatro estatísticas para o teste foi negada a hipótese nula de ausência de cointegração para as cinco regiões. Esse resultado indica que existe relação de longo prazo que permite o uso do estimador DOLS para todas as regiões.

\subsubsection{Resultados das estimativas regionais}

Os testes econométricos indicam para o uso do estimador GLS com correção para autocorrelação e heterocedasticidade e o uso do estimador DOLS para todas as regiões brasileiras. Assim como foi feito para as estimativas de todo o período, primeiro o modelo é estimado sem as dummies interadas e após isso elas são adicionadas. Na Tabela 8, são apresentados os resultados dos principais parâmetros para o curto e longo prazo para o modelo sem as dummies.

A maioria dos resultados foi como esperado, ou seja, elasticidades de longo prazo maiores que as de curto prazo. Elasticidade-renda e elasticidade-cruzada positivas e elasticidade-preço da demanda positiva. Porém, talvez por conta da diminuição dos graus de liberdade, a elasticidade-cruzada de longo prazo e a elasticidade-renda de curto prazo da região Centro-Oeste apresentaram sinais negativos ${ }^{22}$.

\footnotetext{
22 Alguns autores retiram o Distrito Federal das análises por região por considerar que os parâmetros do DF se assemelham mais aos das regiões Sudeste e Sul do País. Em relação aos resultados da Tabela 8, foi testado estimar
} 
Tabela 8. Elasticidades de curto e longo prazo por região sem as dummies

\begin{tabular}{cccccc}
\hline Elasticidade CP & Centro-Oeste & Sul & Sudeste & Norte & Nordeste \\
\hline Ep & $-1,34^{* * *}$ & $-1,53^{* * *}$ & $-1,37^{* * *}$ & $-1,89^{* * *}$ & $-1,50^{* * *}$ \\
Ec & $0,46^{* *}$ & $0,72^{* * *}$ & $0,83^{* * *}$ & $1,32^{* * *}$ & $0,93^{* * *}$ \\
Er & $-0,07$ & 0,20 & $0,67^{* * *}$ & $0,99^{* * *}$ & $1,04^{* * *}$ \\
$\mathrm{n}$ & 476 & 357 & 476 & 833 & 1071 \\
\hline Elasticidade LP & & & & & \\
\hline Ep & $-0,64^{* * *}$ & $-4,83^{* * *}$ & $-3,07^{* * *}$ & $-6,86^{* * *}$ & $-3,96^{* * *}$ \\
Ec & $-\mathbf{1 , 6 8 ^ { * * * }}$ & $2,53^{* * *}$ & $4,98^{* * *}$ & $12,46^{* * *}$ & $2,80^{* * *}$ \\
Er & $0,91^{* *}$ & 0,42 & $0,81^{* *}$ & $0,81^{* * *}$ & $0,77^{* *}$ \\
$\mathrm{n}$ & 480 & 360 & 480 & 840 & 1080 \\
\hline
\end{tabular}

Nota: $\left({ }^{*}\right),(* *)$ e $\left(^{* * *}\right)$ indicam o grau de significância estatística, respectivamente, de $10 \%, 5 \%$ e $1 \%$. a) A elasticidade de curto prazo foi obtida a partir do estimador GLS com correção para heterocedasticidade e erros autocorrelacionados. b) A elasticidade de longo prazo foi obtida a partir das estimativas do estimador DOLS. c) As diferenças das amostras do curto para o longo prazo ficam por conta da não necessidade de serem feitas estimativas em diferença no estimador DOLS (com exceção do parâmetro da frota). d) No curto prazo, os parâmetros para o frete tiveram sinais positivos, diferente do esperado, mas os parâmetros não foram significativos. No longo prazo, para todas as regiões, o frete (omitido na tabela) teve parâmetros negativos e significativos a $1 \%$ em três das cinco regiões.

Fonte: Elaboração própria.

A região Norte apresentou as maiores elasticidades no curto prazo, com a maior elasticidade-preço, a maior elasticidade-cruzada e a segunda maior elasticidade-renda. Os resultados foram os esperados, especialmente a respeito da elasticidade-renda e preço. Isso porque se espera que as regiões mais pobres tenham maior sensibilidade a preços e maior deslocamento do consumo por conta de variações na renda. Ainda a respeito da elasticidade-renda de curto prazo, o etanol chega a ser um produto de luxo $(\mathrm{Er}>1)$ na região Nordeste, e quase isso na região Norte, tamanha a variação do consumo em relação aos deslocamentos da renda.

Na Região Norte, dois resultados chamaram a atenção, não pelo sinal dos parâmetros estimados, mas pela magnitude deles. As elasticidades, mesmo que de longo prazo, para o preço do etanol $(-6,86)$ e para o preço da gasolina $(12,46)$ pareceram superestimadas. Talvez por conta do reduzido consumo da região, pequenos aumentos já resultem em elasticidades tão grandes. Como não foram encontrados estudos que esti-

as regressões sem o DF, o resultado da elasticidade-renda mudou de sinal (coeficiente foi de 0,16 ), porém, continuou não sendo significativo. E o resultado da elasticidade-preço cruzada continuou negativo, porém, nessa nova regressão foi não significativo. mem essa demanda para as regiões, não foi possível obter um parâmetro para comparação, mas apenas olhando a história das estimativas do setor energético, elasticidades maiores que 10 não são compatíveis com a natureza do produto, mesmo no longo prazo.

O mesmo procedimento usado com toda a amostra foi aplicado às estimativas com as dummies $D_{1}, D_{2}$, e $D_{3}$ para verificar se houve mudança nas elasticidades no período pré e pós-flex, sendo repetido para as estimativas por região. Mais uma vez são reportados apenas os principais coeficientes obtidos, sendo omitidas as dummies anuais e mensais e as outras variáveis explicativas (frete e frota). Tem-se na Tabela 9 a comparação das elasticidades nos períodos pré e pós-flex.

Na especificação com as dummies, os resultados para o curto prazo foram os esperados em todas as regiões: sinais positivos para elasticidade-cruzada e elasticidade-renda, negativos para elasticidade-preço e aumento da elasticidade-preço e elasticidade-cruzada no período após 2006. As elasticidades-preço e cruzada aumentaram em todas as regiões no curto prazo. Em relação à elasticidade-renda, essa não mostrou variações significativas, sendo a maioria das dummies com valores próximos de zero ou não estatisticamente diferentes de zero. 
Mensuração das Elasticidades-preço da Demanda, Cruzada e Renda no Mercado de Etanol Brasileiro:

um estudo usando painéis cointegrados

Tabela 9. Diferenças nas elasticidades nos períodos pré e pós-flex (por região)

\begin{tabular}{|c|c|c|c|c|c|}
\hline Variáveis & Centro-Oeste & Sul & Sudeste & Norte & Nordeste \\
\hline \multicolumn{6}{|c|}{ Elasticidades de curto prazo no pré-flex } \\
\hline Ep & $-0,93^{* * *}$ & $-1,14^{* * *}$ & $-1,11^{* * *}$ & $-1,49 * * *$ & $-1,01^{* * *}$ \\
\hline Ec & $0,07^{*}$ & 0,28 & $0,60^{* *}$ & $0,95^{* * *}$ & $0,65^{* * *}$ \\
\hline Er & 0,15 & 0,45 & $0,69^{* * *}$ & $0,64^{* *}$ & $1,24^{* * *}$ \\
\hline \multicolumn{6}{|c|}{ Elasticidades de curto prazo no pós-flex } \\
\hline Ep & $-1,75^{* * *}$ & $-2,29 * * *$ & $-2,05^{* * *}$ & $-3,45^{* * *}$ & $-2,66^{* * *}$ \\
\hline Ec & 0,70 & 1,41 & $1,10^{*}$ & $2,39 * * *$ & $1,86^{* * *}$ \\
\hline Er & 0,12 & 0,38 & $0,69^{* * *}$ & $0,64^{* * *}$ & 1,22 \\
\hline \multicolumn{6}{|c|}{ Elasticidades de longo prazo no pré-flex } \\
\hline Ep & $-3,27^{* * *}$ & $-5,35^{* * *}$ & $-3,17^{* * *}$ & $-7,01^{* * *}$ & $-4,16^{* * *}$ \\
\hline Ec & $-2,14^{* * *}$ & $3,69^{* * *}$ & $4,91^{* * *}$ & $12,79^{* * *}$ & $2,90^{* * *}$ \\
\hline Er & 0,32 & $0,42^{* * *}$ & $0,80^{* *}$ & $0,80^{* * *}$ & $0,76^{* *}$ \\
\hline \multicolumn{6}{|c|}{ Elasticidades de longo prazo no pós-flex } \\
\hline Ep & $-3,13^{* *}$ & $-2,34^{* * *}$ & $-2,20^{* * *}$ & $-1,17^{* * *}$ & $-0,75^{* * *}$ \\
\hline Ec & $0,29 * * *$ & $2,76^{* *}$ & $0,67^{* * *}$ & $5,03^{* * *}$ & $1,35^{* * *}$ \\
\hline Er & 0,02 & 0,36 & 1,11 & 1,26 & 0,68 \\
\hline
\end{tabular}

Nota: $\left({ }^{*}\right),\left({ }^{* *}\right)$ e $\left(^{* * *}\right)$ indicam o grau de significância estatística, respectivamente, de $10 \%, 5 \%$ e $1 \%$.

Fonte: Elaboração própria.

As regiões mais pobres (Norte e Nordeste) apresentaram maiores elasticidades de longo prazo no período pré-flex. Comparando a região com ela mesma, as elasticidades-preço e cruzada diminuíram de forma geral no longo prazo (resultado semelhante ao encontrado na Tabela 7). Novamente, o resultado é atribuído à possibilidade de troca de combustível ter saído do longo para o curto prazo, diminuindo as elasticidades de longo prazo e aumentando as de curto prazo.

Além dos gargalos logísticos, outras explicações para as diferenças regionais na demanda podem ser atribuídas às diferenças tributárias. Mas, considera-se que estas já são manifestadas nos preços, sendo um componente desses ${ }^{23}$. Pode-se questionar que a variável "frete" também seja um componente dos preços do etanol, mas a introdução da variável não resultou em problemas sérios de multicolinearidade.

${ }^{23}$ Para mais explicações sobre as diferenças tributárias no mercado de combustíveis leves, ver Cavalcanti (2011) e Lima (2011).

\section{Comparação com outros estudos}

A comparação com estudos internacionais é válida, porém, pouco pode agregar sobre a acurácia do presente artigo, uma vez que são realidades totalmente diferentes, principalmente no que diz respeito à elasticidade e substitutibilidade dos combustíveis. Por isso, a comparação feita aqui se dá apenas com estudos feitos para o Brasil. Outra observação é a ausência de referências na literatura que estimassem a demanda para as regióes brasileiras, o que faz com que seja possível apenas a comparação com as estimativas da amostra agregada. As comparações com as estimativas de curto prazo podem ser vistas na Tabela 10.

A Tabela 10 separa os trabalhos que estimam a elasticidade utilizando apenas um período e os que utilizam o período pré e pós-flex. Em ambos os casos, as estimativas do presente estudo no curto prazo não são muito diferentes dos dois trabalhos usados na comparação. Entretanto, comparando-se as estimativas de longo prazo, existe discrepância nas estimativas utilizando séries temporais, conforme mostram os resultados da Tabela 11. 
Tabela 10. Comparação com outros trabalhos nacionais - elasticidades de curto prazo

\begin{tabular}{|c|c|c|c|}
\hline Pré-Flex & Ep & Er & Ec \\
\hline Serigati, Correia e Pedrosa (2010) - Série de tempo & $-0,96$ a $-1,33$ & - & 0,74 a 1,47 \\
\hline Presente trabalho - Painel & $-0,96$ a $-1,12$ & 0,45 a 0,51 & 0,58 a 0,64 \\
\hline \multicolumn{4}{|l|}{ Pós-Flex } \\
\hline Serigati, Correia e Pedrosa (2010) - Série de tempo & $-1,81$ a $-2,42$ & - & 1,50 a 2,01 \\
\hline Presente trabalho - Painel & $-2,09$ a $-2,13$ & 0,40 a 0,47 & 1,23 a 1,27 \\
\hline \multicolumn{4}{|l|}{ Período Inteiro (regressões sem dummies) } \\
\hline Souza (2010) - Painel & $-1,26$ e $-1,82$ & 0,45 e 0,20 & - \\
\hline Farina et. al. (2010) - Séries temporais & $-1,23$ & - & 1,45 \\
\hline Santos (2012) - Painel & $-1,25$ & 0,55 & 1,18 \\
\hline Presente trabalho - Painel & $-1,42$ a $-1,53$ & $-0,42$ a 0,49 & 0,73 a 0,86 \\
\hline
\end{tabular}

Fonte: Elaboração própria, com base no formato encontrado em Souza (2010) e Serigati, Correia e Pedrosa (2010).

Tabela 11. Comparação com outros trabalhos - Longo Prazo

\begin{tabular}{lccc}
\hline \multicolumn{1}{c}{ Parâmetros LP } & Ep & Er & Ec \\
\hline Presente Estudo - Painel & $-3,30$ & 2,82 & 0,91 \\
Randow, Fontes e Carminati (2010) - Séries temporais & $-11,26$ & 12,79 & 0,46 \\
Santos (2012) & $-8,45$ & 3,72 & 7,99 \\
\hline
\end{tabular}

Fonte: Elaboração própria.

Embora os sinais tenham sido os mesmos, a magnitude das elasticidades-renda e preço de Randow, Fontes e Carminati (2010) foram bastante elevadas, ainda mais se for considerada a interpretação da elasticidade de que aproximadamente $10 \%$ de variação positiva no preço e negativa na renda derrubaria a zero a demanda por etanol.

Apenas nos estudos de Farina et al. (2010) e Randow, Fontes e Carminati (2010) tem-se que a elasticidade-cruzada do etanol supera a elasticidade-preço. Ou seja, a variação da demanda do produto é mais sensível à variação do substituto do que à variação do seu próprio preço.

Os resultados do presente estudo são próximos em relação ao estudo de Santos (2012) no curto prazo. O mesmo não acontece nas elasticidades de longo prazo, em que as elasticidades encontradas aqui são menores. Este fato parece um avanço, uma vez que uma das ressalvas feitas pelo autor é que as elasticidades de longo prazo encontradas por seu estudo provavelmente estariam superestimadas.

\section{Considerações finais}

Os resultados deste artigo indicam que o etanol é um bem elástico a preço tanto no curto quanto no longo prazo. No período da amostra (2001 a 2011), a elasticidade-preço da demanda por etanol ficou entre $-0,96$ e $-1,12$ no curto prazo (estimativas sem as dummies), resultados compatíveis com a teoria econômica e próximos aos obtidos por trabalhos anteriores.

A elasticidade-preço de longo prazo para o Brasil foi de $-3,30$ (estimativa sem as dummies). $\mathrm{O}$ resultado foi o esperado tanto a respeito do sinal negativo quanto a respeito de uma maior magnitude do que a elasticidade de curto prazo. Em comparação com os estudos encontrados para o longo prazo, Randow, Fontes e Carminati (2010) e Santos (2012), o presente artigo apresenta elasticidades menores, o que parece um avanço em função dos dois estudos apresentarem elasticidades muito elevadas, $-11,26$ para o primeiro e $-8,45$ para o segundo. 
Em todas as especificações, tanto para o curto quanto para o longo prazo, o sinal da elasticidade cruzada do etanol foi positivo, fato que denota a substitutibilidade entre os dois combustíveis. As estimativas da elasticidade cruzada para o Brasil ficaram por volta de 0,81 e 2,82 para o curto e longo prazo, respectivamente (modelo considerando todo o período). Com relação ao efeito da entrada dos carros flex-fuel, as elasticidades-preço e cruzada de curto prazo aumentaram no período pós-flex. O resultado foi oposto para as mesmas elasticidades no longo prazo.

A elasticidade-renda de curto prazo não teve grandes mudanças tanto nas estimativas considerando todo o período quanto no modelo com as dummies. No período pré e pós-flex a mudança no curto prazo foi de apenas -0,04, redução que na literatura mundial é geralmente atribuída à maior necessidade dos veículos por conta do aumento das distâncias percorridas diariamente, mas que aqui, provavelmente, também se deve ao aumento da renda no País e, por consequência, uma menor parte desta ser alocada para o transporte.

Sobre as políticas públicas para o mercado do etanol, corroborando os resultados de estudos anteriores, o etanol se mostrou um bem elástico a preço, possibilitando que os estímulos/desestímulos à sua demanda sejam feitos via mercado. E espera-se que, com o crescimento da renda média, ocorra um incremento na demanda por etanol, indicando que existe necessidade de planejamento de longo prazo tanto para os produtores quanto para o governo, para que o mercado não sofra aumentos bruscos nos preços por conta do desabastecimento.

As autoridades governamentais devem levar em conta a política de impostos no setor de combustíveis, pois, como visto, as elasticidades variam entre as regiões e ao longo do tempo (curto e longo prazo), o que indica que tais políticas têm importantes consequências do ponto de vista de perdas de bem-estar, tanto para os consumidores como para os produtores, afetando todo o mercado de combustíveis.

Nas estimativas para as regiões, considerando as estimativas para todo o período, as maiores elasticidades foram obtidas para as regiões Norte e Nordeste, fato que já era esperado em função dos menores níveis de renda das citadas regiões. A região Centro-Oeste teve elasticidade-cruzada de longo prazo negativa e estatisticamente significativa para a regressão considerando todo o período, que pode ser atribuído ao fato de que a substitutibilidade entre os dois combustíveis é bastante reduzida no período pré-flex. Quando a amostra foi dividida em dois períodos, o resultado para a mesma região foi: elasticidade-cruzada negativa apenas no período pré-flex, corroborando a justificativa.

No restante, os parâmetros para as regiões corresponderam aos resultados esperados, seguindo a linha dos obtidos nas estimativas para todo o Brasil. A elasticidade-preço foi negativa em todas as especificações, para todas as regiões, variando de -0,93 (região Centro-Oeste) até -1,49 (região Norte). Ou seja, se as políticas visam aumentar o consumo de etanol nestas regiões, uma redução no imposto do etanol pode aumentar o consumo deste produto em períodos de oferta estável, com reflexos no bem-estar dos consumidores e impactos na demanda e consumo de gasolina.

Vale ressaltar que o presente estudo possui algumas lacunas que podem ser preenchidas no futuro. Em relação à inclusão da variável frete, por exemplo, espera-se que, com o aumento da amostra para os reais dados de frete para os estados brasileiros seja possível a produção de estudos em que não seja necessário construir tal variável, possibilitando, assim, estimativas mais precisas. Também com o aumento das amostras, poderão ser feitas estimativas para os estados brasileiros de modo a obter parâmetros ainda mais precisos e possibilitando políticas públicas ainda mais focadas do que as regionais.

Como agenda de pesquisa futura, são sugeridos estudos que utilizem microdados de forma semelhante ao procedimento de Anderson (2008) para o consumo de etanol como alternativa à gasolina nos EUA. Com dados desagregados foi possível para esse autor extrair maior quantidade de informações sobre as preferências dos consumidores. Em trabalhos em que as obser- 
vações são feitas por posto de abastecimento, estado, ou ainda mais agregados, não é possível fazer considerações precisas sobre as preferências individuais.

\section{Referências bibliográficas}

ANDERSON, S. The Demand for Ethanol as a Gasoline Substitute. Environmental Protection. 69 p. 2008.

ANFAVEA. Anuário da Indústria Automobilística Brasileira - 2010. Disponível em: <http://www.anfavea. com.br/anuario.html>.

BANERJEE, A. e CARRION-I-SILVESTRE, J. L. L. Cointegration in panel data with breaks and cross-section dependence, 2010.

BRASIL. Agência Nacional de Petróleo, Gás Natural e Biocombustíveis (ANP). Ministério de Minas e Energia. Sistema de Levantamento de Preços. Disponível em: $<$ http://www.anp.gov.br/>. Acesso em: 01 maio 2011.

BRASIL. Empresa de Pesquisa Energética. Balanço Energético Nacional (BEN) - 2011. Ano base: 2010. Rio de Janeiro: EPE, 2011.

BRASIL. Ministério da Agricultura Pecuária e Abastecimento (MAPA). Disponível em: < http://www.agricultura.gov. br/> . Acesso em: 01 maio 2011.

BRITISH PETROLEUM (BP). Statistical Review of World Energy - 2011. Disponível em: < http://www. bp.com/sectionbodycopy.do?categoryId $=7500 \&$ conte ntId $=706848>$. Acesso em: 28 jun. 2011.

CAVALCANTI, M. C. B. Tributação relativa etanolgasolina no Brasil: competitividade dos combustíveis, arrecadação do estado e internalização de custos de carbono. Tese de Doutorado. Rio de Janeiro: Coppe/ UFRJ, 2011.

CHEUNG, K-Y. e THOMSON, E. The Demand for Gasoline in China: A Cointegration Analysis. Taylor and Francis Journals, v. 31, n. 5, p. 533-544, 2004.

CHOI, I. Instrumental Variables Estimation of a Nearly Nonstationary, Heterogeneous Error Component Model. Journal of Econometrics, v. 109, 1-32, 2002.

DAHL, C. A. e STERNER, T. N. S. Analysing gasoline demand elasticities: a survey. Energy Economics, n. 13, p. 201-210, 1991.

ESPEY, M. Gasoline demand revisited: an international meta-analysis of elasticities. Energy Economics, v. 20, p. 273-295. 1998.
FARINA, E., VIEGAS, C., LACERDA, P. e GARCIA, C. Mercado e Concorrência do Etanol. In: SOUSA, E. L. de e MACEDO, I. de C. (Org.). Etanol e Bioeletricidade: A cana de açúcar no futuro da matriz energética. São Paulo: Editora LUC, p. 226-311, 2010.

FERREIRA FILHO, J. B. de S. e HORRIDGE, M. Ethanol Expansion and Indirect Land Use Change in Brazil. Policy Studies, 2011.

GOLDEMBERG, J. e GUARDABASSI, P. The potential for first generation ethanol production from sugarcane. Wiley Interscience, p.17-24, 09 dez. 2009.

GREEN, W. Econometric Analysis. 4. ed. Prentice-Hall, 2000.

HADRI, K. Testing for stationarity in heterogeneous panel data. Econometrics Journal, v. 3, n. 2, p. 148-161, 2000.

HAUSMAN, J. A. Specification Tests in Econometrics, Econometrica, v. 46, n. 6, p. 1251-1271.

HAYASHI, F. Econometrics. Princeton University Press, 2000.

IM, K., PESARAN, M. H. e SHIN, Y. Testing for unit roots in heterogeneous panels. Journal of Econometrics, v. 115 , p. 53-74, 2003.

KAO, C. Spurious Regression and Residual-Based Tests for Cointegration in Panel Data. Journal of Econometrics, v. 90, p. 1-44, 1999.

$\mathrm{KAO}$, C. e CHIANG, M.-H. On the Estimation and Inference of a Cointegrated Regression in Panel Data. Advances in Econometrics, v. 15, p. 179-222, 2000.

LIMA, N. C. A formação dos preços do etanol hidratado no mercado brasileiro de combustíveis. Tese (Doutorado) Universidade de São Paulo. São Paulo, Brasil, 2011.

MARK, N. C. e SUL, D. Cointegration Vector Estimation by Panel Dynamic OLS and Long-Run Money Demand. Oxford Bulletin of Economics and Statistics, v. 65, p. 655680, 2003.

MÁTYÁS, L. e SEVESTRE, P. The econometric of painel data: fundamentals and recent developments in theory and pratice. 3. ed. Springer, 2008, $953 \mathrm{p}$.

NAPPO, M. A Demanda por gasolina no Brasil: uma avaliação de suas elasticidades após a introdução dos carros bicombustível. Dissertação (Mestrado) - Escola de Economia de São Paulo da Fundação Getúlio Vargas, São Paulo, Brasil, 2007.

PEDRONI, P. Panel Cointegration; Asymptotic and Finite Sample Properties of Pooled Time Series Tests, with an Application to the PPP Hypothesis. Indiana University Working Papers in Economics. 1995. 
PESARAN, M. H. A simple panel unit root test in the presence of cross section dependence. Journal of Applied Econometrics, v. 22, p. 265-312, 2007.

PRAIS, S. J. e WINSTEN, C. B. Trend Estimators and Serial Correlation. Cowles Commission Discussion Paper No. 383, Chicago. 1954.

RAMANATHAN, R. Short and long-run elasticities of gasoline demand in India: an empirical analysis using co-integration techniques. Energy Economics, v. 21, n. 4, p. 321-330, 1999.

RANDOW, B. M. V. e FONTES, R. M. O. e CARMINATI, J. G. de O. Estimativas das elasticidades-preço e renda da demanda por álcool combustível no Brasil. $48^{\circ}$ Congresso da Sociedade Brasileira de Economia Administração e Sociologia Rural, 2010.

SANTOS, G. Fuel demand in Brazil in a dynamics panel data approach. Energy Economics, p. 229-240, v. 36, 2012.

SCHUNEMANN, L. A Demanda de gasolina automotiva no Brasil: o impacto nas elasticidades de curto e longo prazo da expansão do GNV e dos carros flex. Dissertação (Mestrado) - Profissionalizante em Economia, Faculdade de Economia e Finanças IBMEC, Rio de Janeiro, Brasil, 2007.

SERIGATI, F. C. e CORREIA, L. B. e PEROSA, B. B. O impacto dos veículos flex-fuel sobre o mercado de combustíveis no Brasil. In: XLVIII Congresso Brasileiro de Economia, Administração e Sociologia Rural, 2010, Tecnologias, Desenvolvimento e Integração Social. Campo Grande, MS. 2010.
SHIKIDA, P. F. A. e PEROSA, B. B. Álcool combustível no Brasil e path dependence. Revista de Economia e Sociologia Rural, Brasília, v. 50, n. 2, jun. 2012.

SINDICATO NACIONAL DA INDÚSTRIA DE COMPONENTES PARA VEÍCULOS AUTOMOTORES (Sindipeças). Levantamento da Frota Circulante Brasileira. Disponível em: <http://www.sindipecas.org.br/>. Acesso em: mai. 2013.

SOUZA, A. Estudo das Demandas de Etanol e Gasolina no Brasil no Período 2001 - 2009. Dissertação (Mestrado) Escola de Economia de São Paulo da Fundação Getúlio Vargas, São Paulo, Brasil, 2010.

TAMARIT, C. R. e GÓMEZ, E. The euro effect on trade: evidence in gravity equations using panel cointegration techniques. Working Papers. InstitutoValenciano de Investigaciones Economicas, 2011.

U.S. Energy Information Administration (EIA). Short-Term Energy Outlook - 2011. Disponível em: < http://www.eia. gov/steo/steo_full.pdf >. Acesso em: 05 jun. 2011.

UNIÃO DA INDÚSTRIA DE CANA DE AÇÚCAR. Setor Sucroenergético - Mapa da Produção. Disponível em: <http://www.unica.com.br/content/ show.asp? cntCode $=\{$ D6C39D36-69BA-458D-A95C815C87E4404D \} >. Acesso em: fev. 2012.

WESTERLUND, J. Testing for error correction in panel data. Oxford Bulletin of Economics and Statistics, v. 69, p. 709-748, 2007.

WORLDWATCH INSTITUTE. German Ministry of Food. Biofuels for Transport: Global Potential and Implications for Sustainable Energy and Agriculture. London: Earthscan, 2006, 452 p. 